\title{
The Prescribing Skills Assessment: a step towards safer prescribing
}

\section{Claire Harrison \\ General practitioner? \\ Associate professor ${ }^{2}$ \\ Sarah Hilmer \\ Head, Department of Clinical Pharmacology ${ }^{3}$ \\ Senior staff specialist, \\ Aged Care ${ }^{3}$ \\ Conjoint professor of geriatric pharmacology ${ }^{4}$ \\ 1 Humphries Road Medical Centre, Frankston South, Victoria \\ 2 Department of General Practice, Faculty of Medicine, Nursing and Health Sciences, Monash University, Clayton, Victoria \\ ${ }^{3}$ Royal North Shore Hospital, Sydney \\ ${ }^{4}$ Northern Clinical School, Faculty of Medicine and Health, University of Sydney}

\section{Keywords}

clinical pharmacology, internship and residency, medical schools, medication error

Aust Prescr 2019;42:148-50 https://doi.org/10.18773/ austprescr.2019.050
Prescribing is a complex task that can involve multiple members of a healthcare team. It encompasses the gathering of information, clinical decision making, communication, review and legal requirements.

Medication errors cause serious harm to patients including death, at an estimated annual global cost of US $\$ 42$ billion.' These errors occur across communities ${ }^{1,2,3}$ and hospitals. ${ }^{1-6}$ In Australia, in 2016-17, $33 \%$ of adverse events during inpatient care were due to 'adverse effects of drugs, medicaments and biological substances'. ${ }^{4}$

In 2017, the World Health Organization (WHO) launched 'Medication Without Harm' as its third Global Patient Safety Challenge.' It aims to reduce the rate of 'severe, avoidable medication-related harm' by $50 \%$ over five years. Australia is a partner in this initiative.

Medication errors are complex and involve multiple stakeholders. ${ }^{1,2,-7}$ Prescribing errors involve underlying factors such as the knowledge and skills of the prescriber, in addition to supervision, patient factors, and prescribing system failures. ${ }^{5-7}$

Despite regulatory support for medication safety, many current Australian medical graduates are not adequately prepared to prescribe safely. The Australian Medical Council stipulates that - 'on entry to professional practice' medical graduates should be able to 'prescribe medications safely, effectively and economically using objective evidence'. ${ }^{8}$ Medication safety is also a requirement of the National Safety and Quality Health Service Standards. ${ }^{9}$ However, work presented at the 2016 National Intern Readiness Forum $^{10}$ and in both the 2017 and 2018 Australian Medical Council / Medical Board of Australia surveys, ${ }^{11,12}$ reported that supervisors and interns have concerns that many are not sufficiently prepared to prescribe upon graduation.

Strategies to enhance the performance of new graduates are likely to have a significant impact on medication safety, given that junior doctors write the majority of prescriptions in hospitals. They have a current error rate of 7-10\%.3,5 However, medical programs face significant challenges to ensure that graduates are prepared for prescribing. The teaching and assessment of clinical pharmacology and therapeutics has declined in many institutions. There are limited opportunities for hands-on experience, due to legal restrictions on student prescribing, compounded recently by difficulties in accessing electronic prescribing systems. The NPS MedicineWise National Prescribing Curriculum provides excellent online teaching modules, but it is not an assessment tool. It is well known that assessment is a powerful driver for student learning.

In response to similar challenges, an online platform called the Prescribing Safety Assessment was developed by the British Pharmacological Society and the Medical Schools Council Assessment in the UK., ${ }^{3,7}$ This teaches and assesses multiple domains relevant to pharmacological therapy, ${ }^{3,7}$ raising the profile of clinical pharmacology and therapeutics in the curriculum. It provides students with a breadth of clinical scenarios in which to legally practise multiple facets of prescribing and medication reviews, with timely feedback. Before full registration as independent prescribers, UK medical graduates are required to demonstrate a basic level of knowledge and skills by passing the Prescribing Safety Assessment.

Since 2016, increasing numbers of medical schools in Australia have implemented an international version of the Prescribing Safety Assessment called the Prescribing Skills Assessment. ${ }^{13}$ This has also involved a collaboration with New Zealand medical schools. A cross-institutional, multidisciplinary group of nearly 50 doctors and pharmacists has regionalised this tool for the Australasian context. The Prescribing Skills Assessment is endorsed as a feasible and appropriate measure of prescribing competency for medical graduates by the Australasian Society of Clinical and Experimental Pharmacologists and Toxicologists. It has the potential to be part of a range of approaches to the assessment of clinical pharmacology, therapeutics and prescribing, as outlined in the recent Assessment of Prescribing in Health (ASPRINH) Project, ${ }^{14}$ particularly taking into account its ability to accommodate large cohort sizes across multiple locations and institutions.

In scenarios from community and hospital-based contexts, candidates sitting the online Prescribing Skills Assessment (practice tests and the main two-hour assessment) are required to consider the results of clinical assessments and investigations to write prescriptions, and to identify inappropriate treatment choices, adverse drug reactions and interactions. They must decide on the most important 
information to communicate to patients to maximise medication safety, in addition to considering how best to monitor the effect of treatment and if any adjustments to therapy are required. It provides experiential learning with feedback in key areas as outlined in WHO's Medication Without Harm strategy. These are 'polypharmacy' and 'high-risk situations', particularly in the young, older people and those with comorbidities involving kidneys and liver.' The tool also gives experience in common areas of deficiency, such as dose selection, $, 2,5,6$ error-prone drugs, ,3,5,5,7 generic drug names, ${ }^{2,5}$ use of safe abbreviations $\mathrm{s}^{2,3}$ and prescribing under time constraints for multiple patients.

The Australian Medicines Handbook has supported the Prescribing Skills Assessment by providing access for students doing the assessments. This linkage encourages the use of a formulary as an integral component of medication safety and counters the misconception that looking things up suggests a lack of competence, ${ }^{5}$ rather than a strategy to reduce errors.

During 2018, there were 31 summative assessments in nine Australian medical schools involving 2225 students. This equates to automated marking of 133,500 medicines safety-related assessment items, including 17,800 prescriptions. Every student had personal access to a similar number of items with automated feedback (in addition to marking) for their own personal study. This is a step towards addressing graduates' calls for more 'hands-on prescribing' in medical school. ${ }^{5}$

In 2019, 12 of the 22 medical schools across Australia and New Zealand are preparing to implement the Prescribing Skills Assessment. An additional two schools have joined this group, to create and standard-set exam items. The aspiration is to contribute to the global reduction in medication errors, through enhanced experiential training and documentation that graduates have achieved an acceptable standard. The current preparedness and performance of the candidates is under analysis, and the effect on medication errors and patient safety is a target for future research.

An educational intervention such as the Prescribing Skills Assessment needs to be accompanied by a suite of other undergraduate and postgraduate initiatives to improve prescribing safety. Examples include additional assessment tools, ${ }^{14}$ the ongoing use of standardised medication charts, ${ }^{2}$ e-prescribing (with decision support), ${ }^{2,7}$ training in medication reconciliation, ${ }^{2}$ interprofessional teamwork, ${ }^{2,7}$ patient-centred shared decision making, ${ }^{7}$ self-care and reflective practice. Training in patient advocacy including 'speaking up',15 and task prioritisation have important roles.
Finally, the rise of prescribing by non-medical healthcare professionals ${ }^{14}$ raises new challenges for co-ordination of patient-centred prescribing. These and other challenges offer future opportunities to adapt the Prescribing Skills Assessment to other disciplines, ${ }^{3}$ with linked interprofessional educational innovations. $\varangle$

The authors are part of a collaboration, working in conjunction with the British Pharmacological Society and the Australasian Society of Clinical and Experimental Pharmacologists and Toxicologists (ASCEPT) to implement the Prescribing Skills Assessment in Australasia.

Acknowledgements to:

- the contributions of Australasian academic, clinical and professional staff who have implemented or are working towards implementation of the Prescribing Skills Assessment from the following institutions: Australian National University, Deakin University, Flinders University, Monash University, University of Auckland, University of Newcastle, University of New South Wales, University of Notre Dame (Sydney), University of Queensland, University of Sydney, University of Western Australia, University of Otago, University of Tasmania, Western Sydney University

- the students who have participated in the Prescribing Skills Assessment and their work to improve competency in medication safety

- Simon Maxwell, Lynne Bollington, Peter Wright, David James and Alex Cole from the British Pharmacological Society/Prescribing Safety Assessment, for their development of the Prescribing Safety Assessment and their support to develop and implement its regionalised version, i.e. the Prescribing Skills Assessment, in Australasia

- $\quad$ Simone Rossi, Jean-Pierre Calabretto, Gundeep Kaur Suri, David Dart from the Australian Medicines Handbook and staff at the New Zealand Formulary, for assistance with linkage between the Prescribing Skills Assessment platform and the respective formularies

- ASCEPT for its support of the Prescribing Skills Assessment

- Medical Deans of Australia and New Zealand for its time to discuss preliminary findings relating to the Prescribing Skills Assessment. 
<ustralian Prescriber

\section{REFERENCES}

1. Word Health Organization. Patient safety. The third WHO Global Patient Safety Challenge: Medication Without Harm; 2017. https://www.who.int/patientsafety/medication-safety/ en [cited 2019 Sep 1]

2. Roughead L, Semple S, Rosenfeld E. Australian Commission on Safety and Quality in Health Care. Literature review: Medication safety in Australia. Sydney: Australian Commission on Safety and Quality in Health Care; 2013. https://www.safetyandquality.gov.au/publications/literaturereview-medication-safety-in-australia [cited 2019 Sep 1]

3. Maxwell SRJ, Coleman JJ, Bollington L, Taylor C, Webb DJ. Prescribing Safety Assessment 2016: delivery of a national prescribing assessment to 7343 UK final-year medical students. Br J Clin Pharmacol 2017;83:2249-58. https://doi.org/10.1111/bcp.13319

4. Australian Institute of Health and Welfare. Admitted patient care 2016-17: Australian hospital statistics. Health services series no. 84. Cat. No. HSE 201. Canberra: AlHW; 2018 https://www.aihw.gov.au/getmedia/acee86da-d98e-428685a4-52840836706f/aihw-hse-201.pdf.aspx?inline=true [cited 2019 Sep 1]

5. Dornan T, Ashcroft D, Heathfield H, Lewis P, Miles J, Taylor D, et al. An in-depth investigation into causes of prescribing errors by foundation trainees in relation to their medical education: EQUIP study. Final report to the General Medical Council. University of Manchester, School of Pharmacy and Pharmaceutical Sciences and School of Medicine; 2009. https://www.gmc-uk.org/-/ media/documents/final-report-prevalence-and-causes-ofprescribing-errors_pdf-28935150.pdf [cited 2019 Sep 1]

6. Coombes ID, Stowasser DA, Coombes JA, Mitchell C. Why do interns make prescribing errors? A qualitative study. Med J Aust 2008;21;188:89-94. https://www.ncbi.nlm.nih.gov/ pubmed/18205581

7. Maxwell SRJ, Webb DJ. Improving medication safety: focus on prescribers and systems. Lancet 2019;394:283-5. https://doi.org/10.1016/S0140-6736(19)31526-0
8. Medical School Accreditation Committee. Standards for assessment and accreditation of primary medical programs by the Australian medical Council 2012. Canberra: Australian Medical Council Limited; 2012. http://www.amc.org.au/ accreditation-and-recognition/accreditation-standards-andprocedures [cited 2019 Sep 1]

9. Australian Commission on Safety and Quality in Health Care. National Safety and Quality Health Service (NSQHS) Standards. https://www.safetyandquality.gov.au/standards/ nsqhs-standards [cited 2019 Sep 1]

10. COAG Health Council. Medical Intern Review. National Intern Work Readiness Forum: summary of proceedings. Australian Health Ministers' Advisory Council; 2016. http://www.coaghealthcouncil.gov.au/medicalinternreview [cited 2019 Sep 1]

11. Australian Medical Council and Medical Board of Australia. AMC/MBA preparedness for internship survey: survey results. 2017. http://www.amc.org.au/wp-content/uploads/ accreditation_recognition/primary-medical-education/ joint_amc mba/mba_results.pptx [cited 2019 Sep 1]

12. Australian Medical Council and Medical Board of Australia. 2018 preparedness for internship survey: national survey results. https://www.medicalboard.gov.au/Search. aspx?q=Preparedness+for+internship+survey [cited 2019 Sep 1]

13. Harrison C, Day R, Dwyer K, Lucas C, Martin J, O'Mara D, et al. Prescribing Skills Assessment - initial results from an Australian cross-institutional pilot. In: Australian \& New Zealand Association for Health Professional Educators. ANZAHPE 2019 conference, 1-4 July 2018, Hobart, Australia. https://www.anzahpe.org/copy-of-2017-conference [cited 2019 Sep 1]

14. The ASPRINH Project's Prescribing Assessment Toolkit https://www.nps.org.au/the-asprinh-project-s-prescribingassessment-toolkit [cited 2019 Sep 1]

15. Okuyama A, Wagner C, Bijnen B. Speaking up for patient safety by hospital-based health care professionals: a literature review. BMC Health Serv Res 2014;14:61. https://doi.org/10.1186/1472-6963-14-61 